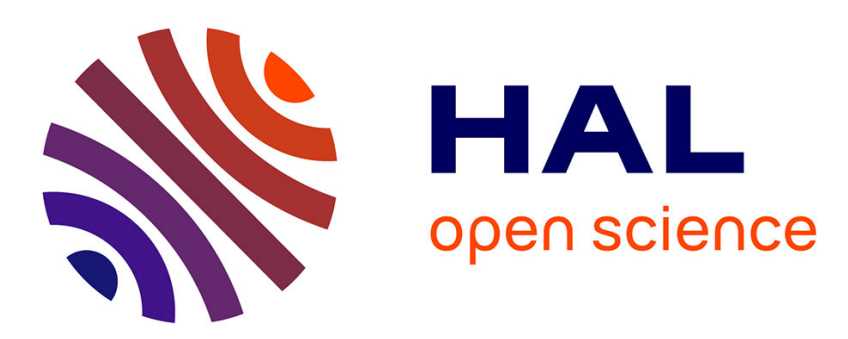

\title{
Habitat availability and geographic isolation as potential drivers of population structure in an oceanic dolphin in the Southwest Indian Ocean
}

Amélia Viricel, Benoit Simon-Bouhet, Laura Ceyrac, Violaine Dulau-Drouot, Per Berggren, Omar A. Amir, Narriman S. Jiddawi, Philippe Mongin, Jeremy J. Kiszka

\section{To cite this version:}

Amélia Viricel, Benoit Simon-Bouhet, Laura Ceyrac, Violaine Dulau-Drouot, Per Berggren, et al.. Habitat availability and geographic isolation as potential drivers of population structure in an oceanic dolphin in the Southwest Indian Ocean. Marine Biology, 2016, 163 (219), 10.1007/s00227-016-2999-3 . hal-01444114

\author{
HAL Id: hal-01444114 \\ https://hal.science/hal-01444114
}

Submitted on 23 Jan 2017

HAL is a multi-disciplinary open access archive for the deposit and dissemination of scientific research documents, whether they are published or not. The documents may come from teaching and research institutions in France or abroad, or from public or private research centers.
L'archive ouverte pluridisciplinaire HAL, est destinée au dépôt et à la diffusion de documents scientifiques de niveau recherche, publiés ou non, émanant des établissements d'enseignement et de recherche français ou étrangers, des laboratoires publics ou privés. 
1 Habitat availability and geographic isolation as potential drivers of population

2 structure in an oceanic dolphin in the Southwest Indian Ocean

4 Amélia Viricel ${ }^{1}$, Benoit Simon-Bouhet ${ }^{1,7}$, Laura Ceyrac ${ }^{2}$, Violaine Dulau-Drouot $^{3}$, Per

5 Berggren $^{4}$, Omar A. Amir ${ }^{5}$, Narriman S. Jiddawi ${ }^{6}$, Philippe Mongin ${ }^{8}$, Jeremy J. Kiszka ${ }^{1,2,7,9^{*}}$

$7 \quad{ }^{1}$ LIttoral ENvironnement et Sociétés (LIENSs), UMR 7266 CNRS-Université de la Rochelle.

8 Institut du Littoral et de l'Environnement, 2 rue Olympe de Gouges, F-17000 La Rochelle,

9 France.

$10{ }^{2}$ Institut de Recherche pour le Développement (IRD), UMR 212 EME (Exploited Marine

11 Ecosystems). Centre de Recherche Halieutique Méditerranéenne et Tropicale, BP 171, F-34203,

12 Sète cedex, France.

$13{ }^{3}$ Globice Réunion, 30 chemin Parc Cabris, Grand Bois, F-97410 Saint Pierre, La Réunion,

14 France.

$15{ }^{4}$ School of Marine Science and Technology, Newcastle University, NE1 7RU, UK

$16{ }^{5}$ Ministry of Livestock and Fisheries, P. O. Box 295, Nyangumi House, Maruhubi Street,

17 Zanzibar, Tanzania.

$18{ }^{6}$ Institute of Marine Sciences, P.O. Box 668, Zanzibar, Tanzania.

$19{ }^{7}$ Centre d'Etudes Biologiques de Chizé (CEBC), UMR 7372 CNRS-Université de la Rochelle.

20 Institut du Littoral et de l'Environnement, 2 rue Olympe de Gouges, F-17000 La Rochelle,

21 France

$22{ }^{8}$ Brigade Nature Ocean Indien, Parc de la Providence, 97400 Saint-Denis, La Réunion, France 
$23{ }^{9}$ Current affiliation: Department of Biological Sciences, Florida International University, 3000

$24 \quad$ NE $151^{\text {st }}$ Street, North Miami, FL33181, USA

25

26

27

*corresponding author: Jeremy Kiszka, jeremy.kiszka@gmail.com, Tel: +1 3059194104

28

29

30

31

32

33

34

35

36

37

38

39

40

41

42

43

44

45

46 


\section{ABSTRACT}

48 Delphinid populations show highly variable patterns of genetic diversity and population structure.

49 Previous studies indicate that habitat discontinuities and geographic isolation are major drivers of

50 population division in cetaceans. Spinner dolphins (Stenella longirostris) are distributed in all

51 tropical oceans, but they are particularly common around islands and atolls. This species occurs

52 in shallow waters at daytime to rest and socialise, and feeds on offshore mesopelagic prey

53 overnight. Here we investigated the genetic population structure of spinner dolphins in the

54 Southwest (SW) Indian Ocean along a west-east geographical gradient, from eastern Africa to the

55 Mascarene archipelago. We combined analyses of 12 microsatellite loci, mtDNA control region

56 sequences, and sighting data to assess genetic differentiation and characterise habitat preferences

57 of these populations. Significant genetic structure among the three sampled sites (Zanzibar,

58 Mayotte and La Réunion) was observed using both types of molecular markers. Overall, our

59 results indicate that geographic isolation, and potentially other factors such as shallow water

60 habitats to rest and socialise, may be important drivers of the genetic population structure of

61 insular spinner dolphins in this region.

62

63 Keywords: spinner dolphin, Stenella longirostris, genetic structure, microsatellites, mtDNA, East

64 Africa.

65

66

67

68

69 


\section{INTRODUCTION}

75 Understanding factors influencing population connectivity has been a central and long-standing 76 research avenue in marine ecology (e.g. Cowen et al. 2000; 2007; Selkoe et al 2008). Past studies

77 have shown that the genetic structure of marine populations is driven by a number of processes,

78 including water currents, sea floor topography, water temperature and life history (e.g., Fullard et

79 al. 2000; Fontaine et al. 2007; Pelc et al. 2009; Ciannelli et al. 2010; Mendez et al. 2011; 2013).

80 In cetaceans, factors that can lead to discontinuous relationships between genetic and geographic

81 distance include habitat characteristics, intra-species niche partitioning (e.g. foraging

82 specialization) and kinship, combined with demographic processes (e.g., Hoelzel 2009; Möller et

83 al. 2007, 2011, Louis et al. 2014a,b; Viricel and Rosel 2014).

85 Beside its fundamental importance in marine ecology, understanding the spatial structure and

86 genetic connectivity of marine populations is also critical for conservation and management

87 purposes. Indeed, while no marine ecosystem is completely unaffected by human activities,

88 threats to populations of marine organisms vary geographically (Halpern et al. 2008). In the

89 Southwest (SW) Indian Ocean for instance, the importance of marine mammal bycatch is

90 spatially variable and it seems to primarily affect inshore species, including coastal delphinids

91 (Kiszka et al 2008). Thus, delimiting biologically meaningful conservation units (i.e., based on

92 population structure assessments) will be a crucial step toward preserving the marine megafauna 93 of this region. 
95 The spinner dolphin (Stenella longirostris) is one of the most abundant and widely distributed

96 tropical delphinids (Perrin 2009). Four subspecies are currently recognised, based on

97 morphological and ecological differences (Perrin and Gilpatrick 1994; Perrin et al. 1999). The

98 Gray's spinner dolphin (S. longirostris longirostris), hereafter the spinner dolphin, is primarily an

99 insular subspecies, and its distribution includes the Atlantic, Indian and Pacific Oceans (Perrin

100 and Gilpatrick 1994). In French Polynesia, Hawaii and the Maldives, spinner dolphins enter

101 atolls, sheltered bays and lagoons through reef channels in the morning and leave in the afternoon

102 to feed offshore overnight (Würsig et al. 1994; Anderson 2005; Gannier and Petiau 2006),

103 essentially on mesopelagic prey (Perrin et al. 1973; Dolar et al. 2003). Around the lagoon of

104 Mayotte, in the Mozambique Channel (SW Indian Ocean), spinner dolphins primarily inhabit the

105 outer slope of the barrier reef to rest and socialise, and rarely enter the lagoon (Kiszka et al.

106 2010a, 2011). During the past 20 years, extensive work has been conducted on the movements,

107 behaviour, social, and genetic population structure of insular spinner dolphins, particularly in the

108 Pacific Ocean (Norris et al. 1994; Karczmarski et al. 2005; Oremus et al. 2007; Andrews et al.

109 2010). These studies highlight that spinner dolphins may form "fission-fusion" societies, with

110 groups forming and separating over short periods of times, such as around the big island of

111 Hawaii (Karczmarski et al. 2005; Andrews et al. 2010). However, social structure may vary

112 according to habitat characteristics and geographical isolation. Indeed, at the remote Midway

113 atoll (Hawaii), spinner dolphins form stable groups with high level of site fidelity, limited

114 emigration/immigration and strong inter-individual associations (Karczmarski et al. 2005). In this

115 region, gene flow is more restricted among populations showing a fluid social structure (the Kona

116 Coast of the island of Hawaii) than among populations with stable social groups (Midway and

117 Kure Atolls) (Andrews et al. 2010). 
119 In the southwestern Indian Ocean, the spinner dolphin is one of the most common small cetacean

120 species in tropical and subtropical waters, particularly around islands and reef complexes off

121 Zanzibar (Amir et al. 2002), Mayotte (Kiszka et al. 2010a, 2011) and the Comoros archipelago

122 (Kiszka et al. 2010c), La Réunion (Dulau-Drouot et al. 2008, Condet and Dulau-Drouot, 2016),

123 Madagascar (Rosenbaum 2003) and Mauritius (Webster et al. 2015). Spinner dolphins

124 (particularly the S. l. longirostris form) are rarely observed in open ocean waters (> 2,000 m), but

125 can occur for short periods of time between islands (particularly in island chains), mostly when

126 undertaking overnight foraging trips (e.g. Kiszka et al. 2011, Mannocci et al. 2013, Thorne et al.

127 2012). As this species occurs in coastal and reef-associated waters, spinner dolphins are impacted

128 by human activities, including past hunting and bycatch off Zanzibar (Stensland et al. 1998, Amir

129 et al. 2012), direct hunting and bycatch in south-western Madagascar (Razafindrakoto et al. 2008)

130 and disturbance from dolphin-watching activities such as on the west coast of Mauritius (Webster

131 et al. 2015). However, the geographical extent of the influence of such direct and indirect effects

132 on populations is unknown.

134 This study aims to characterise genetic diversity and population structure of spinner dolphins in 135 the SW Indian Ocean, particularly from Zanzibar (Tanzania), Mayotte (Comoros archipelago)

136 and La Réunion (Mascarene archipelago) (Fig. 1). These islands were selected because they are

137 located along a west-east gradient, from continental waters of Africa (Zanzibar) to the most

138 isolated and remote oceanic islands (La Réunion). We also characterise depth preferences of

139 spinner dolphins at these sites to evaluate their reliance on shallow-water habitat and to estimate

140 habitat size around the two oceanic islands. Resting habitat availability has been suggested to

141 influence population size and dispersal in other island-associated spinner dolphin populations

142 (Andrews et al. 2010). We evaluate the relationship between our estimations of genetic diversity 
143 and habitat size: islands with more suitable habitats are expected to sustain greater population

144 sizes, which would maintain greater genetic diversity. Geographic distances separating the coasts

145 of the three sites are greater than $900 \mathrm{~km}$. Considering previous knowledge gathered in the

146 Pacific (Andrews et al. 2006; Oremus et al. 2007; Andrews et al. 2010), we hypothesised that

147 geographic isolation is a major driver of the genetic population structure of spinner dolphins in

148 this region, and that sampled islands should contain genetically distinct populations.

151 MATERIAL AND METHODS

153 Sample collection and DNA extraction

154 In total, tissue samples collected from 69 individual spinner dolphins off Zanzibar ( $\mathrm{n}=21)$,

155 Mayotte ( $\mathrm{n}=29)$ and La Réunion ( $\mathrm{n}=19)$ were available for this study (Fig. 1). For Zanzibar,

156 muscle tissues were collected from bycaught animals in drift gillnets between 2000 and 2004 and

157 were stored frozen at $-20^{\circ} \mathrm{C}$. Samples from Mayotte and La Réunion were collected during

158 dedicated biopsy surveys undertaken in territorial waters from 2006 to 2011 from small boats.

159 Biopsy attempts were made opportunistically, when groups and individuals were easily

160 approachable and when conditions were optimal (Beaufort $<2$, dolphins closely approaching the

161 boat). Optimal weather conditions allowed stability of the research boat and better chances to

162 sample the animals successfully and safely (Kiszka et al. 2010b). Blubber and skin biopsies were

163 collected using a crossbow (BARNETT Veloci-Speed ${ }^{\circledR}$ Class, 68-kg draw weight and

164 BARNETT Panzer V Class, 68-kg draw weight) with Finn Larsen (Ceta-Dart, Copenhagen,

165 Denmark) bolts and tips (dart 20-mm long, 7-mm-diameter). Biopsy samples were preserved

166 individually in 90\% ethanol before shipping and subsequent analysis. Biopsy sampling was 
167 conducted under French scientific permit \#78/DAF/2004 (September 10, 2004) and permit

168 \#032/DAF/SEF/2008 (May 16, 2008) for Mayotte and MC/2009/336 for La Réunion. Genomic

169 DNA was extracted from $25 \mathrm{mg}$ of tissue (muscle or skin) using a Nucleospin Tissue kit

170 (Macherey-Nagel) following the manufacturer's protocol.

171

172 Microsatellite genotyping and mitochondrial DNA (mtDNA) sequencing

173 Twelve microsatellite loci previously optimized for S. longirostris were genotyped (Table 1).

174 PCR reactions included $20 \mathrm{ng}$ of genomic DNA, $0.5 \mathrm{U}$ Taq polymerase, $0.25 \mathrm{mM} \mathrm{dNTPs}, 1.5$

$175 \mathrm{mM} \mathrm{MgCl} 2,1 X$ PCR Buffer, $0.125 \mu \mathrm{M}$ of each primer in a $20 \mu \mathrm{L}$ final volume. PCR profiles

176 were as follows: initial 5 min denaturation step at $94^{\circ} \mathrm{C}$ followed by 35 cycles of $30 \mathrm{~s}$ at $94^{\circ} \mathrm{C}, 30$

$177 \mathrm{~s}$ at a specific annealing temperature (see Table 1 ), $45 \mathrm{~s}$ at $72^{\circ} \mathrm{C}$, and by a final 7 -min extension

178 step at $72^{\circ} \mathrm{C}$. All PCRs were conducted in a Techne TC-5000 thermocycler. PCR products were

179 visualized using polyacrylamide gels on the LICOR 4300 DNA Analyser. Allele sizes were

180 determined by eye using a size standard, and by two different researchers to ensure consistency in

181 scoring.

182

183 A portion of the mtDNA control region was amplified using primers Dlp-1.5 (5'-

184 TCACCCAAAGCTGRARTTCTA-3') (Baker et al. 1998) and Dlp-8G (5’-

185 GGAGTACTATGTCCTGTAACCA-3') (Dalebout et al. 2005). PCR reactions included 0.5 U

186 Taq polymerase, $0.25 \mathrm{mM}$ dNTPs, $1.5 \mathrm{mM} \mathrm{MgCl}_{2}$, 1X PCR Buffer, $0.125 \mu \mathrm{M}$ of each primer and

$187 \sim 50 \mathrm{ng}$ of genomic DNA in a $50 \mu \mathrm{L}$ reaction volume. PCRs were conducted in a Techne TC-

1885000 thermocycler using the following profile: initial 5 min denaturation step at $94^{\circ} \mathrm{C}$ followed

189 by 35 cycles of $30 \mathrm{~s}$ at $94^{\circ} \mathrm{C}, 30 \mathrm{~s}$ at $54^{\circ} \mathrm{C}, 45 \mathrm{~s}$ at $72^{\circ} \mathrm{C}$, and by a final 7 -min extension step at 
$19072^{\circ} \mathrm{C}$. PCR products were purified and sequenced by Genoscreen (Lille, France). Sequences were

191 edited in Chromas sequence viewer v. 2.33 (Chromas Technelysium) and were aligned using

192 BioEdit v.5.0.6 (Hall 1999).

193

194 Microsatellite analyses

195 We tested for departures from Hardy-Weinberg or linkage equilibrium within each sampled site 196 using Genepop v. 4.2 (Raymond and Rousset 1995) with 10,000 dememorizations, 1,000 batches

197 and 10,000 iterations per batch. The sequential Bonferroni technique (Holm 1979) was applied to

198 correct for multiple tests. The presence of null alleles and scoring errors was assessed using

199 Micro-checker v. 2.2.3 (van Oosterhoot et al. 2004) within each site. We searched for potential

200 duplicates within biopsied animals by comparing their multi-locus genotypes (i.e., searching for

201 identical genotypes in the dataset, and for genotypes with less than three different alleles overall)

202 using Genalex v. 6.41 (Peakall and Smouse 2006). The mitochondrial haplotypes of samples with

203 matching microsatellite genotypes were compared to confirm they were duplicates of the same

204 individual. We investigated whether related individuals were included in the dataset by

205 calculating maximum-likelihood estimates of pairwise relatedness using ML-Relate (Kalinowski

206 et al. 2006). To avoid biases in population inferences that could result from family structure

207 (Anderson and Dunham 2008), we removed one individual from each pair of potential relatives,

208 i.e., individuals showing a pairwise relatedness value greater than 0.45 (as in Viricel and Rosel

209 2014). Allele richness, observed and expected heterozygosity were calculated using FSTAT v.

$210 \quad$ 2.9.3.2 (Goudet 1995) and Arlequin v. 3.5.1.2 (Excoffier and Lischer 2010), respectively. These

211 molecular diversity indices were calculated for the whole dataset and for each site separately. 
213 Population structure was assessed using a Bayesian approach implemented with Structure v. 2.3.4

214 (Pritchard et al. 2000), which infers the number of populations $(K)$ present in a dataset based on

215 assumptions of Hardy-Weinberg and linkage equilibria within populations. Analyses were

216 conducted using the admixture and correlated allele frequencies models, with and without prior

217 information on individual location (option "LOCPRIOR"). Including prior information on sample

218 locations can improve population inferences, particularly when the level of population

219 differentiation is weak or recent (Hubisz et al. 2009). To verify that using prior information did

220 not artificially result in distinct clusters, we conducted additional Structure runs with the

221 LOCPRIOR option after randomizing the sample location information in the input file. Three

222 randomized input files were created. All Structure runs included 300,000 Markov chain Monte

223 Carlo iterations and a 50,000 step burn in. Ten replicate runs were performed for $K$ values

224 between 1 and 5. Convergence was assessed by examining alpha and likelihood plots, and by

225 comparing individual membership probabilities across replicate runs. The best $K$ was chosen by

226 comparing mean log probabilities among $K$ values, and when $K=1$ was ruled out, by applying

227 Evanno’s method using $\Delta K$ (Evanno et al. 2005).

229 To assess genotypic variation among individuals and among the three locations, we applied a

230 principal component analysis (PCA) to the microsatellite data using the package adegenet

231 (Jombart 2008) in R v. 3.1.2 (R Core Team, 2015). In the PCA, allele frequencies were scaled

232 using the centring option. An analysis of molecular variance (AMOVA, Excoffier et al. 1992)

233 was conducted in Arlequin v. 3.5.1.2. (Excoffier and Lischer 2010) to estimate genetic

234 differentiation among the three islands. Pairwise $F_{\text {ST }}$ estimates were calculated and significance

235 was assessed using 10,000 permutations. We tested for isolation by distance (IBD) by conducting 
236 a Mantel test comparing pairwise genetic distances $\left(F_{\mathrm{ST}} /\left(1-F_{\mathrm{ST}}\right)\right.$, Rousset 1997$)$ with $\log -$

237 transformed (base 10) geographic distances among sampling locations. Geographic distances

238 between population pairs were calculated as the Euclidean distance between the approximate

239 centres of the areas where samples were collected. The Mantel test was performed using IBDWS

240 v. 3.23 (Jensen et al. 2005) with 10,000 randomizations. Finally, we investigated the occurrence

241 of private alleles in each population identified using Genalex v. 6.41.

243 MtDNA sequence analyses

244 Diversity indices (haplotype and nucleotide diversities) were calculated for each site using

245 Arlequin. We used JModeltest v. 0.1.1 (Guindon and Gascuel 2003; Posada 2008) and the Akaike

246 Criterion to determine the most appropriate model of substitution given our sequence alignment.

247 AMOVAs comparing the populations identified using Structure were performed in Arlequin.

248 Genetic differentiation was measured using both $F_{\mathrm{ST}}$ and $\Phi_{\mathrm{ST}}$. For $\Phi_{\mathrm{ST}}$, distances between

249 haplotypes were calculated using the model of substitution selected with JModeltest. Significance

250 was assessed using 10,000 permutations. We evaluated IBD as described above for microsatellite

251 data. A median-joining network was constructed using Network v.4.6.1.2 (Bandelt et al. 1999)

252 with default parameters to represent relationships among haplotypes.

254 Habitat size

255 In order to relate patterns of genetic structure and availability of habitat used by spinner dolphins, 256 we created spinner dolphin habitat maps based on their depth preferences around Zanzibar,

257 Mayotte and La Réunion. From 2004 to 2008, sighting data were collected around Mayotte ( $\mathrm{n}=$ 258168 sightings in 224 days of survey) and La Réunion ( $\mathrm{n}=51$ sightings in 278 days of survey) 
260 sampling protocols). For surveys undertaken around Mayotte and La Réunion, the sampling

261 effort did not follow predefined transects and was not homogeneous. However, both surveys

262 covered shallow inshore waters, the outer slope of the reef and deep oceanic habitats (depth >

263500 m around Mayotte: Kiszka et al. 2011 and depth > 1,000 m around La Réunion: Dulau-

264 Drouot et al. 2008). For Zanzibar, as sighting data were unavailable, we used geographic

265 locations of bycatch events that were recorded during a bycatch monitoring program coordinated

266 by the Institute for Marine Sciences, University of Dar es Salaam, based on Zanzibar between

2672000 and 2007 ( $n=27$ records). These data were used to determine habitat preferences of spinner

268 dolphins using depth as the main variable. We chose to focus habitat analyses on depth as it was

269 previously identified as one of the main explanatory variables explaining spinner dolphin

270 distribution patterns in this region (Kiszka et al. 2011, Condet \& Dulau-Drouot 2016) and in

271 other parts of the world (e.g. Thorne et al. 2012). Depth data were extracted from the

272 GEBCO_2014 Gridded bathymetric dataset (30 arcsecond resolution) hosted on the British

273 Oceanographic Data Center (http://www.bodc.ac.uk). We considered that the preferred habitat

274 corresponded to the depth range where $95 \%$ of spinner dolphin observations were made. Thus,

275 we excluded $2.5 \%$ of the deepest and $2.5 \%$ of the shallowest observations to determine i) the

276 preferred depth range for Mayotte and La Réunion separately (we did not include Zanzibar in this

277 comparison as observations from Zanzibar come from bycatch events and are thus not directly

278 comparable to sighting data from the other two islands), ii) the overall preferred depth range for

279 the three islands together. For the second calculation, group size information available for

280 sightings around Mayotte was taken into account. Our reasoning was that using group size

281 information (when available) better reflects the preferred habitat of these populations (i.e.

282 observing large groups in an area carries more weight than observing a single individual). We 
283 computed the total area available within the depth range limits obtained for the three islands

284 together, and mapped these areas for Mayotte and La Réunion. It was not computed for Zanzibar

285 since available habitat within this depth-range is virtually infinite along the East African

286 continental shelf relative to the two islands. The retrieval of individual depths, the computation of

287 projected surfaces and the mapping were all performed with the marmap package v0.9.2 (Pante

288 and Simon-Bouhet 2013) in R v3.1.2.

291 RESULTS

293 Microsatellite data

294 Each sample was genotyped at 8 to 12 loci. No significant departure from Hardy-Weinberg or

295 linkage equilibrium was observed (after sequential Bonferroni correction) in the three sampled

296 sites. Furthermore, no scoring errors were identified using Micro-checker. Possible null alleles

297 were detected for loci EV94 and 415/416 in Mayotte; however, since this issue was restricted to

298 one site, we kept these two loci in all analyses. A duplicate sample was identified (100\%

299 matching genotypes and haplotype) in La Réunion, where the same individual was biopsied

300 twice. Five pairs of potential relatives were detected using ML-Relate: two pairs in La Réunion,

301 one pair in Zanzibar, and two pairs in Mayotte. Only one individual from each pair was kept in

302 population analyses conducted with both types of markers (mtDNA and microsatellites) to avoid

303 the potential bias of including relatives. The final microsatellite dataset included 63 individuals

304 (Table 2). The number of alleles per locus ranged from six to 25 (Table 1). Observed

305 heterozygosity and mean allele richness were similar among the three sites (Table 2). 
307 No population subdivision was found when Structure was run without prior information (Fig. 2a).

308 Conversely, genetic structure was detected when individual location was used as prior

309 information. The most likely number of populations present in the dataset was three based on

310 comparison of the mean log probabilities and $\Delta K$ (Fig. 2b), and corresponded to the three

311 sampled sites (Fig. 2c): within each site, all individuals were assigned to the same cluster with

312 high ancestry proportions $(q>0.8$, mean $q=0.95)$. Randomizing sample locations in the

313 Structure input file and applying the LOCPRIOR option resulted in no structure being detected

314 by the program (most likely $\mathrm{K}=1$; see Appendix 1).

316 The first principal component of the PCA separated individuals from Mayotte from the other two

317 locations, while the third principal component showed two separate clusters for individuals from

318 La Réunion and Zanzibar (Appendix 2). Some overlap in the PC space was observed among the

319 three clusters. Together, the first three principal components explained $12.7 \%$ of the total

320 genotypic variation. The AMOVA conducted among the three populations revealed relatively

321 weak, but significant genetic differentiation (Overall $F_{\mathrm{ST}}=0.020 p<0.0001$; Table 3). The

322 Mantel test conducted to examine IBD was not significant $\left(r=0.21, R^{2}=0.04, p=0.51\right)$. Private

323 alleles were detected within each of the three sites (Mayotte: 31; La Reunion: 9; Zanzibar: 11).

325 MtDNA data

326 The final control region sequence alignment was 720 bp-long and included 28 unique haplotypes

327 (Genbank accession \# XXXXXXXX-XX). The sequence alignment included 42 substitutions and 328 no indels. The model selected using JModeltest was Tamura-Nei (Tamura and Nei 1993) with a 329 gamma correction $(\boldsymbol{\alpha}=0.726)$. Analyses of mitochondrial sequences supported the population 
330 structure detected using microsatellite loci: significant differences in mitochondrial haplotype

331 frequencies (after sequential Bonferroni correction) were observed among all sites using $F_{\mathrm{ST}}$

332 (Overall $F_{\mathrm{ST}}=0.084 p<0.0001$; Table 4). However, none of the pairwise comparisons were

333 significant when distances among haplotypes were incorporated in the AMOVA (i.e., using $\Phi_{\mathrm{ST}}$,

334 Table 4). The test for IBD was not significant $\left(r=0.96, R^{2}=0.93, p=0.17\right)$. There was one

335 shared haplotype between La Réunion and Zanzibar, and three shared haplotypes between

336 Mayotte and Zanzibar. Mayotte and La Réunion had no haplotypes in common (Fig. 3). No

337 obvious phylogeographic structure was observed on the haplotype network.

339 Habitat size

340 Comparing the depth distribution data of the two oceanic islands revealed that the preferred depth

341 range of spinner dolphins around La Réunion (16 to $935 \mathrm{~m}$ ) was larger than the one calculated for

342 Mayotte (5 to $175 \mathrm{~m}$ ). When all observation data are combined, the locations used by $95 \%$ of the

343 individuals sighted around Zanzibar, Mayotte and La Réunion have a depth range of 9 to $162 \mathrm{~m}$.

344 The total surface available around Mayotte and La Réunion within this depth-range (9 to $162 \mathrm{~m}$ )

345 was 1,036 and $327 \mathrm{~km}^{2}$, respectively (Figure 4). The habitat surface corresponding to spinner

346 dolphins' depth preferences is thus three times larger in Mayotte than in La Réunion.

349 DISCUSSION

350

351 Marine organisms with high dispersal capacities can show weak genetic structure across large

352 geographic distances. For instance, the short-beaked common dolphin (Delphinus delphis) and 
353 the Portuguese dogfish (Centroscymnus coelolepis) each form a single panmictic population

354 across the eastern Atlantic (Veríssimo et al. 2011; Moura et al. 2013). However, even low levels

355 of genetic differentiation can correspond to restricted levels of dispersal in a demographic sense

356 and can be associated with adaptive divergence (e.g., Knutsen et al. 2011; Aykanat et al. 2015),

357 and therefore represent important findings in terms of conservation and management.

358 In highly dispersive marine organisms, incorporating spatial information as prior information in

359 genetic analyses can help reveal genetic differentiation (Selkoe et al. 2008), as illustrated in the

360 present study. Indeed, we did not detect any structure when using a Bayesian approach to detect

361 the number of genetically distinct populations based on microsatellite data alone. Including prior

362 information about sample location in the Bayesian analysis allowed retrieving three populations,

363 corresponding to the distinct islands that were sampled. Our results are in accordance with

364 expectations of Latch et al. (2006) and Hubisz et al. (2009), as the $F_{\mathrm{ST}}$ estimates we obtained

365 from analysis of microsatellite data fell right in the range where genetic structure can remain

366 undetected without prior information $\left(0.01<F_{\mathrm{ST}}<0.03\right)$. This approach (Structure with

367 LOCPRIOR: Hubisz et al. 2009) does not seem to falsely inflate genetic structure as shown in

368 previous studies (e.g. Christie et al. 2010; Russello et al. 2012; Viricel 2012). Results from the

369 three randomizations we conducted indicate the genetic clusters we observed using prior

370 information are biologically significant (Appendix 1). Furthermore, the Mantel test comparing

371 pairwise genetic and geographic distances was not significant, suggesting IBD did not confound

372 our Structure results. The three distinct populations inferred from Structure and observed in the

373 PCA based on nuclear data were supported by the significant genetic differentiation estimated

374 with mitochondrial DNA sequences using $F_{\mathrm{ST}}$. Possible explanations for the lack of significant

375 differentiation observed using $\Phi_{\mathrm{ST}}$ are that the observed genetic differentiation is recent and that 
376 not enough time has passed for new mutations to accumulate within populations; or that

377 migration rates among these populations are greater than the mutation rate of the mitochondrial

378 DNA control region. In these cases, incorporating distances among haplotypes in the AMOVA

379 can increase noise in the analysis (Bird et al. 2011), rendering $\Phi_{\mathrm{ST}}$ less informative than $F_{\mathrm{ST}}$.

381 The preferred depth range of spinner dolphins we inferred from sighting and bycatch data (i.e.,

382 for the three locations analysed together) confirmed that the species is associated with relatively

383 shallow-water habitat at these locations, which corresponds to their resting grounds. The wider

384 depth range observed for the population of La Réunion (also described in Dulau-Drouot et al.

385 2008) may reflect the very narrow continental shelf of the island, with depth increasing rapidly

386 from the shore, compared to Mayotte. In fact, a recent habitat modelling study showed that

387 despite the wide depth range of spinner dolphin observations aroung La Réunion, most sightings

388 occur between 51 and $63 \mathrm{~m}$ of depth, within a "core habitat" also characterised by flat and light-

389 colored seabeds (Condet \& Dulau-Drouot 2016). Geographic isolation and the reliance of spinner

390 dolphins on appropriate shallow-water resting habitat during daytime are likely factors causing

391 and/or maintaining divergence between populations occupying Mayotte and La Réunion.

392 Although we cannot tease apart the relative role of each of these two factors, hypotheses can be

393 made based on what has been observed in other small delphinid species. Indeed, large

394 geographic distance from continental waters does not seem to be a sufficient driver to cause

395 restricted gene flow in pelagic dolphins found around oceanic islands as illustrated by population

396 structure studies on Atlantic spotted dolphin (Stenella frontalis) and common bottlenose dolphin

397 (T. truncatus) populations from the Azores: the pelagic morphotypes within these two species

398 form panmictic populations over large distances, from the Azores to offshore waters of the 
400 other hand, some pelagic island-associated delphinids show restricted gene flow across short

401 distances within an archipelago such as common bottlenose dolphin populations around Hawaii

402 (Martien et al. 2012), or the rough-toothed dolphin (Steno bredanensis), which displays long-

403 term site fidelity around the Society Islands (French Polynesia), and fine-scale genetic

404 differentiation between two islands only $170 \mathrm{~km}$ apart (Oremus et al. 2012). Thus, daily reliance

405 on near-shore, insular habitats may be a predominant driver of population structure in pelagic

406 delphinids, even more so than geographic isolation.

407

408 The genetic subdivision we observed is consistent with other studies conducted on S. longirostris

409 in the Pacific Ocean, which indicated that insular populations are generally discrete. Levels of

410 genetic differentiation were similar to those observed among Society (French Polynesia) and

411 Hawaii archipelago (Oremus et al., 2007; Andrews et al. 2010). Spinner dolphins found around

412 islands of the Society Archipelago (French Polynesia) form relatively closed communities

413 showing strong island fidelity (Oremus et al. 2007). Gene flow among these communities is

414 restricted, despite the short geographic distances separating some of these islands (i.e. tens of

415 kilometers). Oremus et al. (2007) suggest that these communities are characterised by a

416 metapopulation dynamics, which would explain the high genetic diversity and large island

417 effective population sizes estimated from their molecular data. In the Hawaiian archipelago, fine-

418 scale genetic structure is also observed, but patterns of gene flow vary according to social

419 structure and habitat availability (Andrews et al. 2010). Overall, both the genetic and social

420 structure of this species seems to be influenced by the availability and extent of resting areas

421 (Karczmarski et al. 2005; Andrews et al. 2010). In Hawaiian populations, genetic differentiation

422 increased with geographic distance among islands. In the present study, the tests for IBD we 
423 conducted for both types of markers were not significant. We have to note, however, that these

424 tests had low statistical power since only three populations were sampled. Thus, future studies 425 analyzing samples from additional islands in the SW Indian Ocean would better allow testing for

426 IBD. Additionally, photo-identification data would complement present findings, as site fidelity

427 may constitute another factor driving population structure in spinner dolphins from the SW

428 Indian Ocean.

429

430 The genetic diversity we measured (Table 2) was similar to what has been reported for this

431 subspecies in French Polynesia (Oremus et al. 2007), and was greater than the diversity observed

432 in Hawaii (Andrews et al. 2010). Despite the genetic differentiation of spinner dolphins from La

433 Réunion and Mayotte, the genetic diversity of these two populations is similar to the diversity of

434 spinner dolphins from the coast of Zanzibar. Factors influencing their population genetic

435 diversity include effective population size (linked to drift) and immigration rates. Given the

436 differences in habitat size among the three sites we compared, the respective local population size

437 of the populations occupying these sites may differ. Thus, we hypothesize that the similar levels

438 of genetic diversity we observe in these populations likely reflect low but recurrent gene flow,

439 which may be sufficient to maintain genetic diversity within island communities. Spinner

440 dolphins from the SW Indian Ocean could thus be under a metapopulation dynamics, similarly to

441 what findings from Oremus et al. (2007) indicate for populations in the Society Archipelago.

442 Alternatively, the genetic divergence we measured could be recent, and these populations may

443 have so far retained ancestral polymorphisms.

444

445 The present study constitutes the first population structure assessment for the spinner dolphin in 446 the SW Indian Ocean and our findings have important conservation implications. Indeed, the 
447 habitat preferences and patterns of restricted gene flow we identified suggest spinner dolphin

448 populations found off Mayotte and La Réunion are demographically independent from each

449 other. Their differentiation makes them potentially vulnerable if directly impacted by human

450 activities, and spinner dolphins found off these two islands should therefore be treated as two

451 distinct conservation units at the national level. Analysing samples from other islands (e.g.

452 Madagascar, Mauritius) within this region would allow further evaluating the genetic isolation of

453 these populations. Bycatch levels of spinner dolphins in gillnets off Zanzibar (Amir et al. 2002)

454 should be considered as a cause of concern, and this issue highlights the need of a population

455 structure assessment along the east coast of Africa. Protecting important resting habitat is an

456 important step toward the conservation of insular spinner dolphin populations. Dedicated surveys

457 help assessing whether current marine protected areas encompass such habitats (e.g. in la

458 Réunion: Dulau-Drouot et al. 2008) and habitat modelling studies (e.g. Thorne et al. 2012,

459 Condet \& Dulau-Drouot 2016) allow identifying key areas where new conservation efforts

460 should be focused.

461

462 Acknowledgements

463 At Mayotte, samples and data from July 2004 to June 2006 were collected during a dolphin

464 research project conducted by the Office National de la Chasse et de la Faune Sauvage (ONCFS,

465 Game and Wildlife Service) and the Agriculture and Forestry Office (Direction de l'Agriculture

466 et de la Forêt). From May 2007 to April 2009, data were collected during a joined programme of

467 the University of La Rochelle, the Office National de la Chasse et de la Faune Sauvage and the

468 Collectivité Départementale de Mayotte. DNA samples were prepared at the Molecular Core

469 Facility at the University of La Rochelle. We would like to thank the Associate Editor and four

470 anonymous reviewers for constructive comments on the manuscript. 


\section{Compliance with ethical standards}

473

474 Funding: Funding was provided by the Conseil Général de Mayotte, the Ministère de l'Energie, 475 l'Ecologie, le Développement Durable et de la Mer (MEEDDM), the University of La Rochelle 476 and the Office National de la Chasse et de la Faune Sauvage. The samples and data collected in 477 Zanzibar was supported by funding grants from SIDA/Sarec. In Reunion, sampling was co478 funded by DEAL-Reunion, BNOI and IRD, as part of the Southwestern Indian Ocean Fisheries 479 Project (SWIOFP).

480 Confict of Interest: The authors declare that they have no conflict of interest.

481 Ethical approval: All applicable international, national, and/or institutional guidelines for the 482 care and use of animals were followed. 


\section{References}

Amir OA, Berggren P, Jiddawi NS (2002) The incidental catch of dolphins in gillnet fisheries in Zanzibar, Tanzania. WIO J Mar Sci 1:155-162

Amir OA, Berggren P, Jiddaw NS (2012) Recent records of marine mammals in Tanzanian waters. J. Cetacean Res. Manage. 12:249-253

Amos B, Schlötterer C, Tautz D (1993) Social structure of pilot whales revealed by analytical DNA profiling. Science 260:670-672

Anderson RC (2005) Observations of cetaceans in the Maldives, 1990-2002. J Cet Res Manag 7:119-135

Anderson EC, Dunham KK (2008) The influence of family groups on inferences made with the program structure. Mol Ecol Resour 8:1219-1229

Andrews KR et al (2006) Patterns of genetic diversity of the Hawaiian spinner dolphin (Stenella longirostris). Atoll Res Bull 543:65-73

Andrews KR et al (2010) Rolling stones and stable homes: social structure, habitat diversity and population genetics of the Hawaiian spinner dolphin (Stenella longirostris). Mol Ecol $19: 732-748$

Aykanat T, Johnston SE, Orell P, Niemelä E, Erkinaro J, Primmer CR. 2015. Low but significant genetic differentiation underlies biologically meaningful phenotypic divergence in a large

Baker C et al (1998) Mitochondrial DNA variation and maternal gene flow among humpback whales of the southern hemisphere. Mar Mamm Sci 14:721-737. phylogenies. Mol Biol Evol 16:37-48. 
Bérubé M, Jorgensen H, McEwing R, Palsbøll PJ (2000) Polymorphic di-nucleotide

509 microsatellite loci isolated from the humpback whale, Megaptera novaeangliae. Mol Ecol

$510 \quad 9: 2181-2182$

511 Bird CE, Karl SA, Smouse PE, Toonen RJ (2011) Detecting and measuring genetic

512 differentiation. In: Koenemann S, Held C, Schubart CD (ed) Crustacean Issues:

513 Phylogeography and Population Genetics in Crustacea, $1^{\text {st }}$ edn. CRC Press, Boca Raton, pp

$514 \quad 31-55$

515 Caldwell M, Gaines MS, Hughes CR (2002) Eight polymorphic microsatellite loci for bottlenose

516 dolphin and other cetacean species. Mol Ecol Notes 2:393-395

517 Christie MR, Johnson DW, Stallings CD, Hixon MA (2010) Self-recruitment and sweepstakes

518 reproduction amid extensive gene flow in a coral-reef fish. Mol Ecol 19:1042-1057

519 Ciannelli L et al (2010) Small-scale genetic structure in a marine population in relation to water

520 circulation and egg characteristics. Ecology 91(10):2918-2930

521 Condet M, Dulau-Drouot V (2016) Habitat selection of two island-associated dolphin species

522 from the south-west Indian Ocean. Cont Shelf Res 125:18-27

523 Cowen RK, Lwiza MMK, Sponaugle S, Paris CB, Olson DB (2000) Connectivity of marine

$524 \quad$ populations: Open or closed? Science 287:857-859

525 Cowen RK, Gawarkiewicz G, Pineda J, Thorrold SR, Werner FE (2007) Population connectivity

526 in marine systems: An overview. Oceanography 20:14-21

527 Dalebout ML et al (2005) Worldwide structure of mtDNA diversity among Cuvier's beaked

528 whales (Ziphius cavirostris): implications for threatened populations. Mol Ecol 14:3353-

$529 \quad 3371$ 
530 Dolar MLL, Walker WA, Kooyman GL, Perrin WF (2003) Comparative feeding ecology of

$531 \quad$ spinner dolphins (Stenella longirostris) and Fraser's dolphins (Lagenodelphis hosei) in the

$532 \quad$ Sulu Sea. Mar Mamm Sci 19:1-1

533 Dulau-Drouot V, Boucaud, V, Rota B (2008) Cetacean diversity off La Réunion Island (France).

$534 \quad$ J M Biol Ass UK 88:1263-1272

535 Evanno G, Regnaut S, Goudet J (2005) Detecting the number of clusters of individuals using the

536 software STRUCTURE: a simulation study. Mol Ecol 14:2611-2620

537 Excoffier L, Lischer HE (2010) Arlequin suite ver 3.5: a new series of programs to perform

538 population genetics analyses under Linux and Windows. Mol Ecol Resour 10:564-567

539 Excoffier L, Smouse P, Quattro J (1992) Analysis of molecular variance inferred from metric

540 distances among DNA haplotypes: Application to human mitochondrial DNA restriction

$541 \quad$ data. Genetics 131:479-491

542 Fontaine MC et al (2007) Rise of oceanographic barriers in continuous populations of a cetacean:

543 the genetic structure of harbour porpoises in Old World waters. BMC Biol 5:30

544 Fullard KJ, Early G, Heide-Jørgensen MP, Bloch D, Rosing-Asvid A, Amos W (2000)

545 Population structure of long-finned pilot whales in the North Atlantic: a correlation with sea

$546 \quad$ surface temperature? Mol Ecol 9:949-958

547 Gannier A, Petiau E (2006) Environmental variables affecting the residence of spinner dolphins

548 (Stenella longirostris) in the Bay of Tahiti (French Polynesia). Aquat Mamm 32:202-211

549 Goudet J (1995) FSTAT (version 1.2.): a computer program to calculate $F$-statistics. J Hered

$550 \quad 86: 485-486$

551 Guindon S, Gascuel O (2003) A simple, fast, and accurate algorithm to estimate large

552 phylogenies by maximum likelihood. Syst Biol 52:696-704 
553 Hall T (1999) BioEdit: a user-friendly biological sequence alignment editor and analysis program

554 for Windows 95/98/NT. Nucl Acid S 41:95-98

555 Halpern BS et al (2008) A global map of human impact on marine ecosystems. Science 319:948-

$556 \quad 952$

557 Hoelzel AR (2009) Evolution of population genetic structure in marine mammal species. In:

558 Bertorelle G, Bruford MW, Hauffe HC, Rizzoli A, Vernesi C (eds) Cambridge University

$559 \quad$ Press, New York, pp 294-318

560 Hoelzel AR, Dahlheim M, Stern SJ (1998) Low genetic variation among killer whales (Orcinus

$561 \quad$ orca) in the eastern North Pacific and genetic differentiation between foraging specialists. J

$562 \quad$ Hered 89:121-128

563 Holm S (1979) A simple sequentially rejective multiple test procedure. Scand J Stat 6:65-70

564 Hubisz MJ, Falush D, Stephens M, Pritchard J (2009) Inferring weak population structure with

565 the assistance of sample group information. Mol Ecol Resour 9:1322-1332

566 Jensen JL, Bohonak AJ, Kelley ST (2005) Isolation by distance, web service. BMC Genetics

$567 \quad$ 6:13. V.3.23 http://ibdws.sdsu.edu/

568 Jombart T. (2008) adegenet: a R package for the multivariate analysis of genetic markers.

$569 \quad$ Bioinformatics 24:1403-1405

570 Kalinowski ST, Wagner AP, Taper ML (2006) ML-Relate: a computer program for maximum-

571 likelihood estimation of relatedness and relationship. Mol Ecol Notes 6:576-579

572 Karczmarski L, Würsig B, Gailey G, Larson KW, Vanderlip C (2005) Spinner dolphin in a

573 remote Hawaiian atoll: social grouping and population structure. Behav Ecol 16:675-685

574 Kiszka J et al (2008) Marine mammal bycatch in the Southwest Indian Ocean: Review and need

575 for a comprehensive status assessment. Western Indian Ocean J Mar Sci 7:119-136 
Kiszka J, Ersts PJ, Ridoux V (2010a) Structure of a toothed cetacean community around a tropical island (Mayotte, Mozambique Channel). Afr J Mar Sci 32(3):543-551

Kiszka J, Simon-Bouhet B, Charlier F, Pusineri C, Ridoux V (2010b) Individual and group behavioural reactions of small delphinids to remote biopsy sampling. Anim Welfare 19:411-

Kiszka J, Breysse O, Vely M (2010c) Preliminary account of cetacean diversity and humpback whale (Megaptera novaeangliae) group characteristics around the Union of the Comoros (Mozambique Channel). Mammalia 74:51-56

Kiszka J, Simon-Bouhet B, Martinez L, Pusineri C, Richard P, Ridoux V (2011) Ecological niche segregation within a community of sympatric dolphins around a tropical island. Mar Ecol Prog Ser 433:273-288

Knutsen H, Olsen EM, Jorde PE, Espeland SH, André C, Stenseth NC. 2011. Are low but

Krützen M, Valsecchi E, Connor RC, Sherwin WB (2001) Characterization of microsatellite loci in Tursiops aduncus. Mol Ecol Notes 1:170-172 clustering software for inferring population substructure and individual assignment at low levels of population differentiation. Conserv Genet 7:295-302

Louis M et al (2014a) Ecological opportunities and specializations shaped genetic divergence in a highly mobile marine top predator. Proc R Soc B 281:20141558 truncatus, in the North-East Atlantic. Mol Ecol 23:857-874 
599 Mannocci L et al (2014) Predicting top predator habitats in the Southwest Indian Ocean.

$600 \quad$ Ecography 37(3):261-278

601 Martien KK et al (2012) Population structure of island-associated dolphins: evidence from

602 mitochondrial and microsatellite markers for common bottlenose dolphins (Tursiops

603 truncatus) around the main Hawaiian Islands. Mar Mamm Sci 28:E208-E232

604 Mendez M et al (2013). Integrating multiple lines of evidence to better understand the

605 evolutionary divergence of humpback dolphins along their entire distribution range: a new

606 dolphin species in Australian waters? Mol Ecol 22: 5936-5948.

607 Mendez M et al (2011) Molecular ecology meets remote sensing: environmental drivers to

608 population structure of humpback dolphins in the Western Indian Ocean. Heredity 107:349-

609361.

610 Möller LM, Valdez FP, Allen S, Bilgmann K, Corrigan S, Beheregaray LB (2011) Fine-scale

611 genetic structure in short-beaked common dolphins (Delphinus delphis) along the East

612 Australian Current. Mar Biol 158:113-126

613 Möller LM, Wiszniewski J, Allen SJ, Beheregaray LB (2007) Habitat type promotes rapid and

614 extremely localised genetic differentiation in dolphins. Mar Freshwat Res 58:640-648

615 Moura AE, Natoli A, Rogan E, Hoelzel AR (2013) Atypical panmixia in a European dolphin

616 species (Delphinus delphis): implications for the evolution of diversity across oceanic

617 boundaries. J Evol Biol 26:63-75

618 Norris KS, Würsig B, Wells RS, Würsig M (1994) The Hawaiian Spinner Dolphin, University of

619 California Press, Berkeley, 408 pp.

620 van Oosterhoot C, Hutchinson W, Wills D, Shipley P (2004) MICRO-CHECKER: software for

621 identifying and correcting genotyping errors in microsatellite data. Mol Ecol Notes 4:535-

$622 \quad 538$ 
623 Oremus M, Poole MM, Steel D, Baker CS (2007) Isolation and interchange among insular 624 spinner dolphin communities in the South Pacific revealed by individual identification and 625 genetic diversity. Mar Ecol Prog Ser 336:275-289

626 Oremus M, Poole MM, Albertson GR, Baker CS (2012) Pelagic or insular? Genetic

627 differentiation of rough-toothed dolphins in the Society Islands, French Polynesia. J Exp Mar $628 \quad$ Biol Ecol 423-433:37-46

629 Palsbøll PJ, Bérubé M, Larsen AH, Jørgensen H (1997) Primers for the amplification of tri- and 630 tetramer microsatellite loci in baleen whales. Mol Ecol 6:893-895

631 Pante E, Simon-Bouhet B (2013) marmap: A package for importing, plotting and analyzing 632 bathymetric and topographic data in R. PLoS ONE 8(9): e73051.

633 doi:10.1371/journal.pone.0073051

634 Peakall R, Smouse PE (2006) GENALEX 6 : genetic analysis in Excel. Population genetic 635 software for teaching and research. Mol Ecol Notes 6:288-295

636 Pelc RA, Warner RR, Gaines SD (2009) Geographical patterns of genetic structure in marine 637 species with contrasting life histories. J Biogeogr 36:1881-1890

638 Perrin WF (2009) Spinner dolphin Stenella longirostris. In: Perrin WF, Würzig B, Thewissen J 639 (ed) Encyclopedia of Marine Mammals, $2^{\text {nd }}$ edn. Academic Press, San Diego, pp 1100-1103 640 Perrin WF, Dolar M, Louella L, Robineau D (1999). Spinner dolphins (Stenella longirostris) of 641 the western Pacific and Southeast Asia: pelagic and shallow-water forms. Mar Mamm Sci 642 15(4):1029-1053

643 Perrin WF, Gilpatrick JW Jr. (1994) Spinner dolphin Stenella longirostris (Gray, 1828). In: 644 Ridway SH and Harrison R (eds) Handbook of marine mammals, Academic Press, London, $645 \quad$ pp 99-128. 
646 Perrin WF, Warner RR, Fiscus CH, Holtz DB (1973) Stomach content of porpoise, Stenella spp., 647 and yellowfin tuna, Thunnus albacares, in mixed-species aggregations. Fish Bull 71:1077-

$648 \quad 1092$

649 Posada D (2008) jModelTest : Phylogenetic model averaging. Mol Biol Evol 25:1253-1256

650 Pritchard JK, Stephens M, Donnelly P (2000) Inference of population structure using multilocus

651 genotype data. Genetics 155:945-959

652 Quérouil S et al (2007) High gene flow in oceanic bottlenose dolphins (Tursiops truncatus) of the $653 \quad$ North Atlantic. Conserv Genet 8:1405-1419

654 R Core Team (2015) R: A language and environment for statistical computing. R Foundation for 655 Statistical Computing, Vienna, Austria. URL http://www.R-project.org/

656 Raymont M, Rousset F (1995) Genepop (version 1.2), population genetics software for exact 657 tests and ecumenicism. J Hered 86:248-249

658 Razafindrakoto Y, Andrianarivelo N, Cerchio S, Rasoamananto I, Rosenbaum H (2008)

659 Preliminary assessment of cetacean incidental mortality in artisanal fisheries in Anakao, 660 southwestern region of Madagascar. WIO J Mar Sci 7(2):175-184

661 Rosel PE, France SC, Wang JY, Kocher TD (1999) Genetic structure of harbour porpoise 662 Phocoena phocoena populations in the northwest Atlantic based on mitochondrial and $663 \quad$ nuclear markers. Mol Ecol 8:541-554

664 Rosenbaum HC (2003) Marine mammals of Madagascar. In: Godman S, Bengston J (eds), The 665 natural history of Madagascar, University of Chicago Press, Chicago, pp 213-216

666 Rousset F (1997) Genetic differentiation and estimation of gene flow from $F$-statistics under 667 isolation by distance. Genetics $145: 1219-1228$

668 Russello MA, Kirk SL, Frazer KK, Askey PJ (2012) Detection of outlier loci and their utility for 669 fisheries management. Evol Appl 5:39-52 
670 Selkoe KA, Henzler CM, Gaines SD (2008) Seascape genetics and the spatial ecology of marine $671 \quad$ populations. Fish Fish 9:363-377

672 Stensland E, Berggren P, Johnstone R, Jiddawi N (1998) Marine mammals in Tanzanian waters: 673 urgent need for status assessment. Ambio 27: 771-774

674 Tamura K, Nei M (1993) Estimation of the number of nucleotide substitutions in the control 675 region of mitochondrial DNA in human and chimpanzees. Mol Biol Evol 10:512-526

676 Thorne LH et al (2012) Predictive modeling of spinner dolphin (Stenella longirostris) resting 677 habitat in the main Hawaiian Islands. PLoS One 7(8) :e43167

678 Valsecchi E, Amos W (1996) Microsatellite markers for the study of cetacean populations. Mol $679 \quad$ Ecol 5:151-156

680 Veríssimo A, McDowell JR, Graves JE (2011) Population structure of a deep-water squaloid 681 shark, the Portuguese dogfish (Centroscymus coelolepis). ICES J Mar Sci 68:555-563

682 Viricel A (2012) Using genetics to assess population structure in three cetacean species and to 683 investigate the etiology of cardiomyopathy in Kogia breviceps. Dissertation, University of $684 \quad$ Louisiana at Lafayette

685 Viricel A, Rosel PE (2014) Hierarchical population structure and habitat differences in a highly 686 mobile marine species: the Atlantic spotted dolphin. Mol Ecol 23:5018-5035

687 Webster I, Cockcroft VG, Cadinouche A (2015) Spinner dolphins Stenella longirostris off south688 west Mauritius: abundance and residency. Afr J Mar Sci 37(1):115-124

689 Würsig B, Wells RS, Norris KS, Würsig M (1994) A spinner dolphin's day. In: Norris KS, 690 Würsig B, Wells RS, Würsig M (eds) The Hawaiian Spinner Dolphin London, University of 691 California Press, pp 65-102 
694

695

696 
698 Table 1. Twelve microsatellite loci genotyped in this study. PCR annealing temperature (Ta), 699 reference, number of alleles, observed $(\mathrm{Ho})$ and expected $\mathrm{He}$ ) heterozygosity are given for $700 \quad$ each locus.

\begin{tabular}{llllll}
\hline Locus & Ta $\left({ }^{\circ} \mathrm{C}\right)$ & Reference & Number of alleles & Ho & He \\
\hline 415/416 & 45 & Amos et al. 1993 & 12 & 0.772 & 0.889 \\
GT575 & 60 & Bérubé et al. 2000 & 10 & 0.679 & 0.778 \\
GT6 & 60 & Caldwell et al. 2002 & 6 & 0.635 & 0.676 \\
AAT44 & 55 & Caldwell et al. 2002 & 10 & 0.770 & 0.710 \\
KWM12a & 46 & Hoelzel et al. 1998 & 10 & 0.889 & 0.844 \\
MK5 & 50 & Krützen et al. 2001 & 13 & 0.786 & 0.912 \\
MK6 & 50 & Krützen et al. 2001 & 18 & 0.879 & 0.931 \\
GATA98 & 54 & Palsbøll et al. 1997 & 9 & 0.655 & 0.804 \\
PPHO142 & 50 & Rosel et al. 1999 & 9 & 0.804 & 0.810 \\
PPHO131 & 57 & Rosel et al. 1999 & 12 & 0.755 & 0.834 \\
EV1 & 47 & Valsecchi and Amos 1996 & 16 & 0.868 & 0.902 \\
EV94 & 54 & Valsecchi and Amos 1996 & 25 & 0.772 & 0.925 \\
\hline
\end{tabular}

701

702 Table 2. Mitochondrial DNA (mtDNA) and microsatellite diversity indices for Stenella

703 longirostris from each site: N, sample size; No. haplo, number of haplotypes; $\pi$, nucleotide

704 diversity; $h$, haplotype diversity; AR, allele richness; $H_{o}$, observed heterozygosity; $H_{e}$,

705 expected heterozygosity

\begin{tabular}{|c|c|c|c|c|c|c|c|c|}
\hline & \multicolumn{4}{|c|}{ mtDNA } & \multicolumn{4}{|c|}{ Microsatellites } \\
\hline & $\mathrm{N}$ & No. haplo & $\pi$ & $h$ & $\mathrm{~N}$ & Mean AR & Ho & $\mathrm{He}$ \\
\hline Zanzibar & 20 & 9 & 0.013 & 0.826 & 20 & 7.1 & 0.747 & 0.790 \\
\hline Mayotte & 19 & 14 & 0.015 & 0.965 & 27 & 8.2 & 0.773 & 0.835 \\
\hline La Réunion & 16 & 9 & 0.012 & 0.900 & 16 & 7.5 & 0.798 & 0.818 \\
\hline
\end{tabular}


706 Table 3. AMOVA results obtained from analysis of microsatellite data from 63 S. longirostris

707 individuals. Pairwise $F_{\mathrm{ST}}$ values are shown below diagonal and corresponding p-values

$708 \quad$ above diagonal.

709

\begin{tabular}{lccc}
\hline & Zanzibar & Mayotte & La Réunion \\
\hline Zanzibar & NA & $<0.001^{*}$ & $<0.001^{*}$ \\
Mayotte & 0.024 & $\mathrm{NA}$ & $0.009^{*}$ \\
La Réunion & 0.025 & 0.013 & $\mathrm{NA}$
\end{tabular}

$710 *$ significant p-value after sequential Bonferroni correction

711

712 Table 4. AMOVA results for mitochondrial DNA sequences. Pairwise $F_{\mathrm{ST}}$ and $\Phi_{\mathrm{ST}}$ values are

713 shown below and above diagonal, respectively.

714

\begin{tabular}{lccc}
\hline & Zanzibar & Mayotte & La Réunion \\
\hline Zanzibar & $\mathrm{NA}$ & 0.050 & 0.014 \\
Mayotte & $0.058^{*}$ & $\mathrm{NA}$ & 0.066 \\
La Réunion & $0.130^{*}$ & $0.067^{*}$ & $\mathrm{NA}$ \\
\hline
\end{tabular}

715 *significant $\mathrm{p}$-value after sequential Bonferroni correction

716

717 
719 Figure 1. Study area and sample locations. Sample sizes are indicated for each site. The $200 \mathrm{~m}$ 720 and 1,000 $\mathrm{m}$ isobaths are represented by darker lines.

721 Figure 2. Bayesian clustering analysis (Structure) results obtained from analysis of 12 microsatellite loci (a) without any prior information and (b) using prior information about sample location (“LOCPRIOR" option). The mean log probability $(\operatorname{LnP}(K))$ is given for each $K$ tested and the $\Delta K$ from Evanno's method is shown between successive $K$ values. (c) The barplot represents individual ancestry proportions for the three populations obtained using the "LOCPRIOR" option.

727 Figure 3. Median-joining network of 28 mitochondrial control region haplotypes observed in 63

728 S. longirostris individuals. Filled circles represent haplotypes and their size is proportional to

729 their frequency in the dataset. Circles are shaded in colours proportionally to the number of

730 individuals from each population (Mayotte: blue; La Reunion: green; Zanzibar: red).

731 Unsampled or extinct intermediate haplotypes are shown as black dots. Each line corresponds to one mutational step, except when a number of mutations is adjacent to it.

733 Figure 4. Maps showing the surface available for daytime resting for spinner dolphins around

734 Mayotte (top) and La Réunion (bottom). These surfaces were estimated based on the

735 preferred depth-range of spinner dolphins in the SW Indian Ocean. Maps include all

736 sightings, including outlier observations that were not used to determine the preferred depth

737 range (see Material and Methods). 
$740 \quad$ Figure 1.

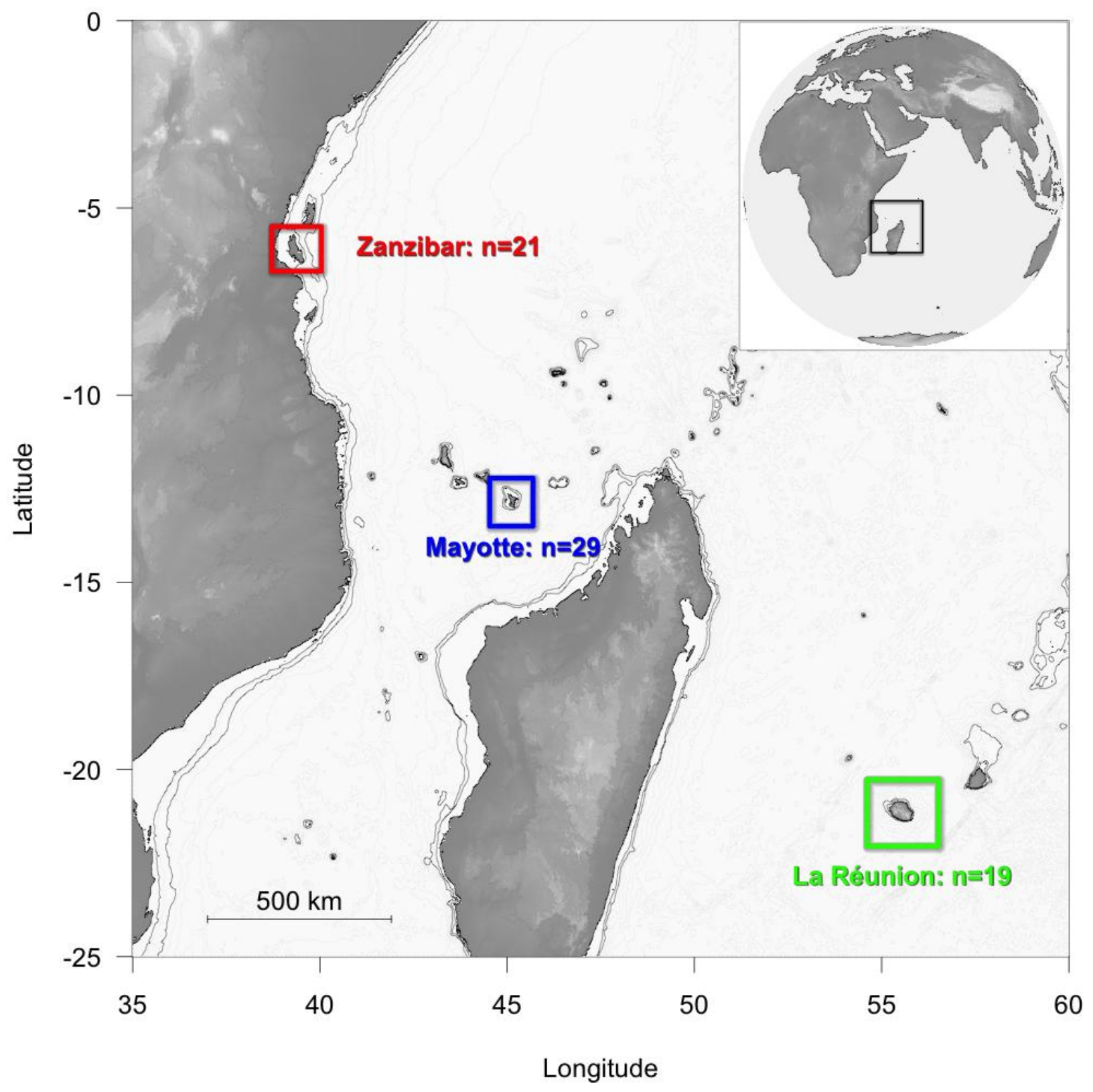


742 Figure 2

a)

\begin{tabular}{lll}
\hline $\boldsymbol{K}$ & $\operatorname{LnP}(\boldsymbol{K})$ & $\boldsymbol{\Delta} \boldsymbol{K}$ \\
\hline $\mathbf{1}$ & $\mathbf{- 2 8 8 5}$ & na \\
2 & -3579 & 3.4 \\
3 & -3078 & 2.2 \\
4 & -3007 & 5.7 \\
5 & -3086 & na \\
\hline
\end{tabular}

b)

\begin{tabular}{lll}
\hline $\boldsymbol{K}$ & $\operatorname{LnP}(\boldsymbol{K})$ & $\boldsymbol{\Delta} \boldsymbol{K}$ \\
\hline 1 & -2885 & na \\
2 & -2856 & 3.0 \\
$\mathbf{3}$ & $\mathbf{- 2 8 0 8}$ & $\mathbf{1 9 . 4}$ \\
4 & -2841 & 0.2 \\
5 & -2877 & na \\
\hline
\end{tabular}

c)

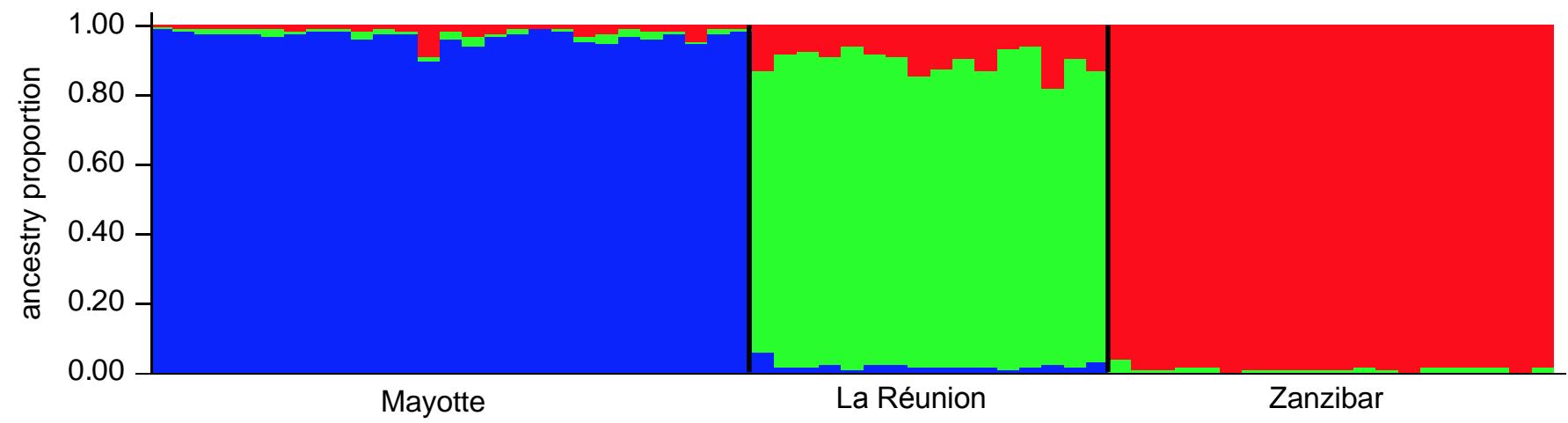


$744 \quad$ Figure 3

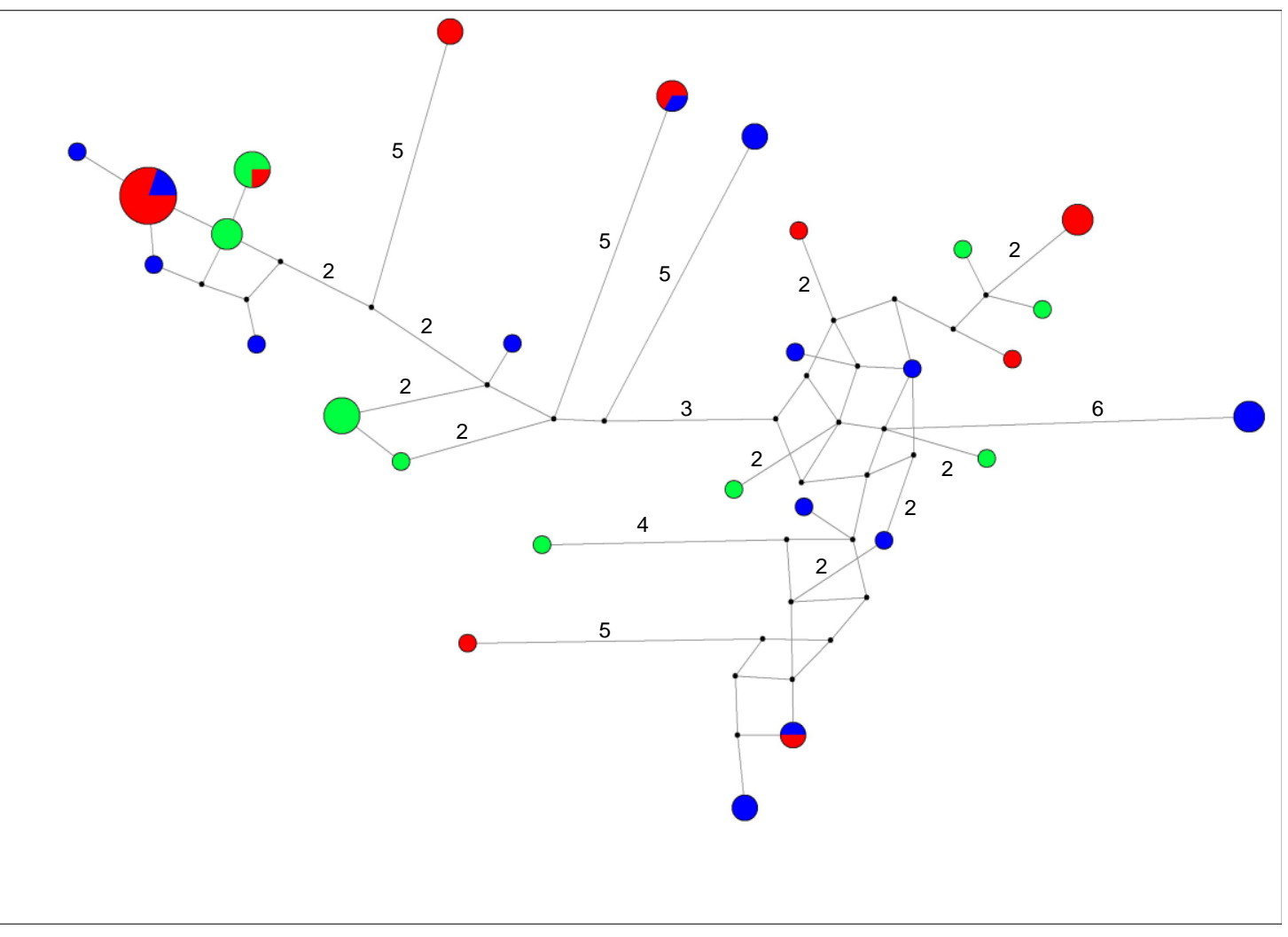




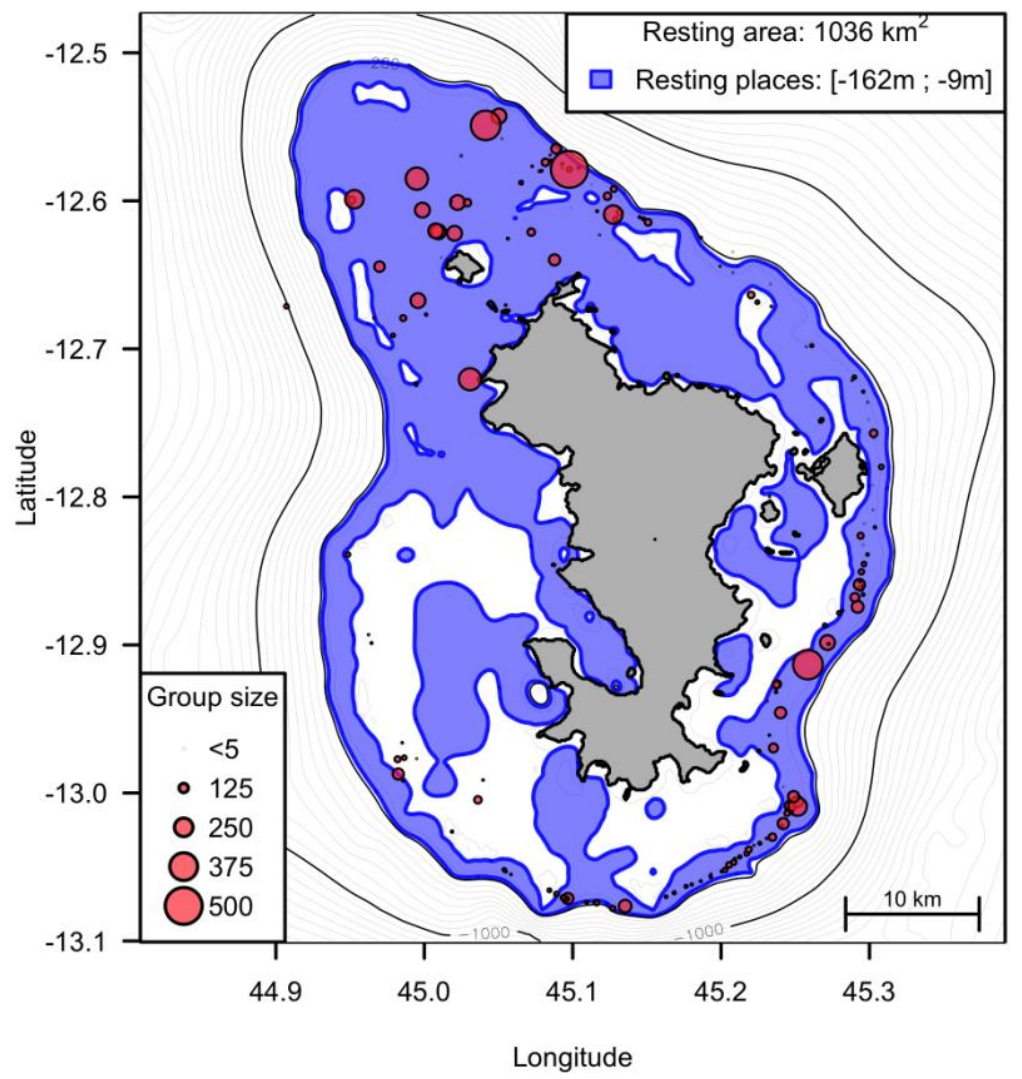

747

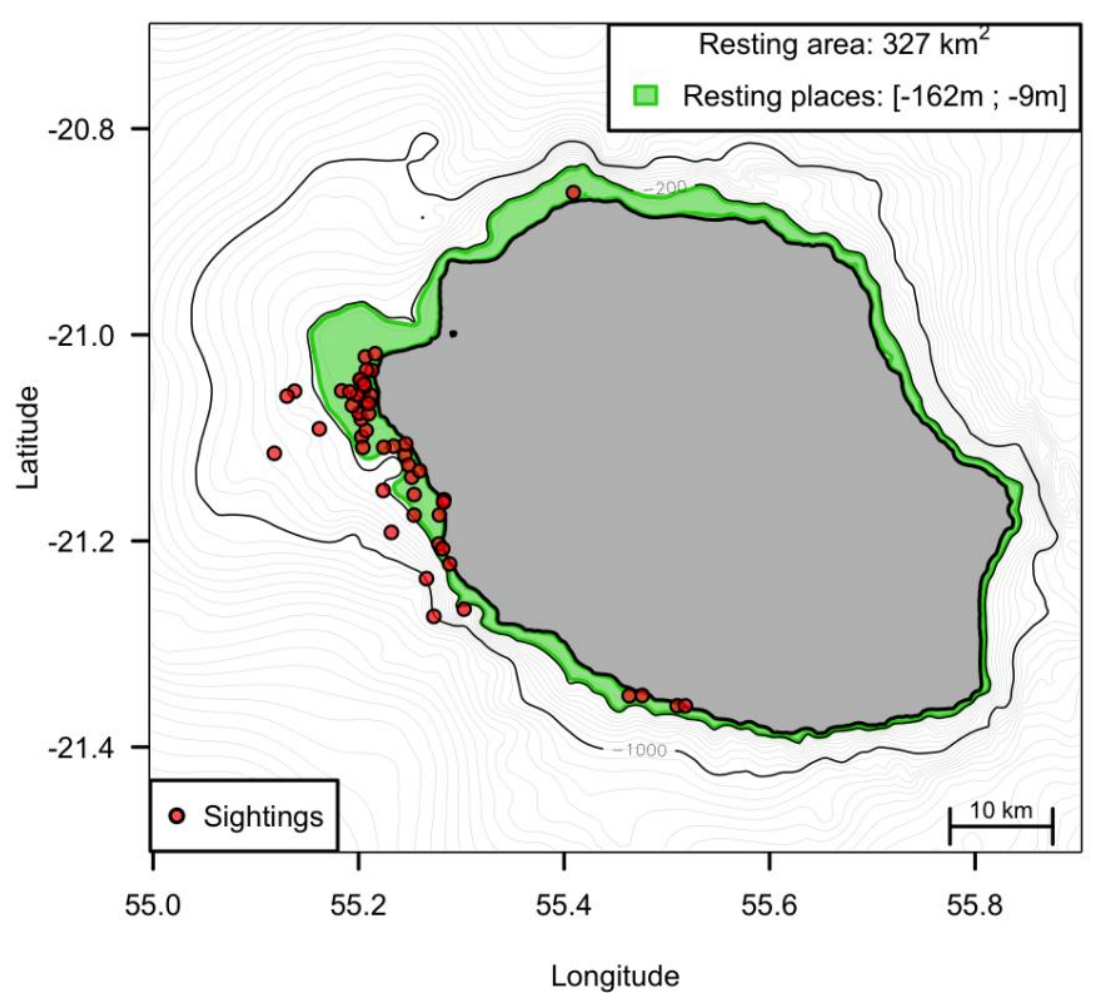

